\title{
Prevalence of spoilage mold in coffee before and after brewing
}

\author{
*Kusumaningrum, H.D. and Rasyidah, M.M. \\ Department of Food Science and Technology, Faculty of Agricultural Technology, Bogor Agricultural \\ University, Bogor 16680 Indonesia
}

\section{Article history: \\ Received: 4 April 2019 \\ Received in revised form: 25 \\ May 2019 \\ Accepted: 28 May 2019 \\ Available Online: 11 June 2019}

\section{Keywords:}

Commercial ground coffee,

Mold counts,

Spoilage mold,

Traditional brewing

\section{DOI:}

https://doi.org/10.26656/fr.2017.3(6).142

\begin{abstract}
Commercial ground coffee must be safe for consumption and comply with the regulation applied in a country. However, the risk of the occurrence of spoilage molds in commercial ground coffee, particularly toxigenic mold originated from coffee cherries or green beans, is still a major concern of the coffee industry. This study evaluated the prevalence of spoilage mold in fifteen brands of commercial ground coffee. The spoilage molds were also determined after traditional brewing (non-filtration brewing). The mold counts were enumerated on dichloran-glycerol $18 \%$ agar by spread plate method. The spoilage molds were also morphologically identified after isolation on malt extract agar and potato dextrose agar. The results showed that low numbers of molds were found in all samples before brewing, in a range of 10 to $200 \mathrm{CFU} / \mathrm{g}$. A total of eleven genera were identified. Aspergillus, Cladosporium and Penicillium were found as the predominating genera. After brewing, molds from genera Alternaria and Aspergillus were still found. However, the total counts decreased to the level between undetected to an average of $3 \mathrm{CFU} / \mathrm{mL}$. This study highlighted that very low levels of spoilage mold was recovered after brewing which may not pose a health risk.
\end{abstract}

\section{Introduction}

The quality of green coffee beans can affect the characteristic of coffee beverages and is still a major concern in the coffee industry worldwide. Once the green beans are contaminated, it can decrease the quality and sensory characteristics of the roasted and brewed coffee, giving the unwanted attributes (Iamanaka et al., 2014). The presence of filamentous molds has been already reported in coffee beans processed in Brazil, Malaysia, Philippines, Thailand, and Saudi Arabia (Silva et al., 2008; Noonim et al., 2008; Alvindia and Acda, 2010; Rahim et al., 2011; Al-Abdalall and Al-Talib, 2012). Aspergillus, Penicillium, Fusarium and Cladosporium have been found as natural coffee contaminants in Brazil (Silva et al., 2008) and present in coffee beans from the field, during fermentation and drying to the warehouse. Alvindia and Acda (2010) also reported that fourteen genera were recovered from coffee beans in the Philippines after harvest and drying. The mold contamination can occur on coffee beans as a result of improper harvesting procedures, inappropriate drying, and inadequate storage conditions. The diversity of the contaminant molds can also be influenced by the region where the coffee beans originated (Noonim et al., 2008;
Couto et al., 2014).

Although the roasting temperature of coffee beans can eliminate the contaminant mold, however, some spores are not completely eliminated and would be carried over in coffee products. Rahim et al. (2011) reported that molds of different genera were still found on eight of twenty commercial black coffee powder samples in Malaysia. Fusarium sp. dominated the contamination, followed by Penicillium sp., Aspergillus sp., and Cladosporium spp. Alvindia and Acda (2010) also reported that nine species from five genera were recovered from 21 samples of roasted coffee bean from retail markets in Philippines. Aspergillus, Penicillium, Chrysosporium, Microascus and Rhizopus were found as coffee contaminants.

Usually, coffee is consumed after hot brewing preparation using a coffee machine or a coffee maker, where filtering is included (Verst et al., 2018). However, despite different modern coffee brewing techniques are available, the traditional brewing process is still popular in Indonesia (Sudiyarto et al., 2012). This type of coffee known as 'kopi tubruk' or mud coffee in Indonesia is prepared by putting the ground coffee in a cup followed by pouring hot water and held for a few minutes before 
serving to let the residues settle down.

Although concerns on the presence of spoilage molds in coffee have been increasing, data on the presence of carried over mold in coffee after brewing have not been widely reported. This study was carried out to determine the presence of mold in coffee before brewing and molds that survive after brewing.

\section{Materials and methods}

\subsection{Samples}

A total of fifteen commercial ground coffee samples were purchased from the supermarket around Bogor, Indonesia. The samples consisted of Robusta, Arabica, and a mix of Arabica-Robusta ground coffee. For each sample, a sample size of $100 \mathrm{~g}$ was collected and subsampled $(25 \mathrm{~g})$ for determination of the mold counts.

From the $100 \mathrm{~g}$ of laboratory sample, $10 \mathrm{~g}$ of the sample was also weighed and brewed in $150 \mathrm{~mL}$ hot water $\left(90^{\circ} \mathrm{C}\right)$ without filtering, representing the traditional practice to prepare mud coffee. This mixture was agitated with a spoon for approximately $10 \mathrm{~s}$ and then placed at room temperature for 4 mins to settle the residue, prior to the mold determination. For $\mathrm{pH}$ measurement, the brewed coffee was further cooled until reaching the room temperature $\left(27 \pm 1^{\circ} \mathrm{C}\right)$.

\subsection{Enumeration of mold counts}

A total of $25 \mathrm{~g}$ of ground coffee was aseptically mixed with $225 \mathrm{~mL} 0.1 \%$ buffered peptone water (Oxoid, UK) in a sterile stomacher bag and homogenized in a stomacher (BagMixer 400P, Interscience, France) for 2 mins to provide the first suspension. For brewed coffee after cooled, the first dilution was made by adding of $25 \mathrm{~mL}$ beverage solution aseptically to $225 \mathrm{~mL} 0.1 \%$ peptone water and homogenized. Serial dilutions were made under aseptic conditions. For each dilution, $0.1 \mathrm{~mL}$ was then pipetted and spread on duplicate plates of solidified dichloran 18\% glycerol agar (DG-18, LabM, UK). Plates were incubated at $25^{\circ} \mathrm{C}$ for 5 days and the colonies were counted and expressed as $\mathrm{CFU} / \mathrm{g}$. All samples were analyzed twice.

\section{$2.3 \mathrm{pH}$ measurement}

The $\mathrm{pH}$ of ground coffee was measured using the first suspension, while the $\mathrm{pH}$ of the brewed coffee was measured after the coffee was cooled to room temperature.

\subsection{Isolation and identification of mold}

Any visible mycelia growth or spores from DG-18 plates were transferred onto malt extract agar (MEA,
Merck, Germany) and potato dextrose agar (PDA, Oxoid, UK) plates for identification. The plates were incubated at $25^{\circ} \mathrm{C}$ for 7 days. Isolates were identified on the basis of macro-morphological properties of colonies and micro-morphological properties of conidia and other structures by referring to the key described by Pitt and Hocking (2009).

\section{Results and discussion}

\subsection{Molds counts in coffee before and after brewing}

The total molds in commercial ground coffee before brewing were found in a range between $10 \mathrm{CFU} / \mathrm{g}$ to 200 $\mathrm{CFU} / \mathrm{g}$ (Table 1). These loads decreased after brewing, between undetected level (no colony) to an average of 3 $\mathrm{CFU} / \mathrm{mL}$. The $\mathrm{pH}$ was in a range of 5.12 to 6.12 before brewing and slightly decreased after brewing to between 5.04 to 5.88. The fact that low numbers of mold were still found after brewing in some coffee samples indicated that the spores of some molds were likely resistant to heat treatment during brewing.

The mold counts found in ground coffee before brewing in this study were comparable with the study conducted by Alvindia and Acda (2010) and by Rahim et al. (2011). Alvindia and Acda (2010) reported that total mold in roasted bean coffee in Philippines was in a range of $5.3 \times 10^{1}$ to $1.4 \times 10^{2} \mathrm{CFU} / \mathrm{g}$. Rahim et al. (2011) reported that commercial black coffee powder samples in Malaysia were contaminated by mold in a range of $<100$ to $1.2 \times 10^{3} \mathrm{CFU} / \mathrm{g}$. The presence of mold in roasted ground coffee was influenced by the place of origin of the coffee beans and the processing methods involved. After roasting, the total mold in coffee beans decreased significantly by 93 to $97 \%$ (Alvindia and Acda, 2010). The presence of mold after roasting might be due to the post-processing contaminations, the heat resistance of mold spores, or associated with insufficient heat treatment during roasting.

\subsection{Mold isolates from coffee before brewing}

As shown in Table 2 and 4, more than 250 mold colonies were found on plates from coffee samples before and after brewing. Some molds with similar morphology were found on some plates. From those colonies, sixty isolates were discovered. Some isolates were not identified. Eleven genera were identified on samples before brewing, i.e. Cladosporium, Penicillium, Aspergillus, Alternaria, Geothricum, Phoma, Rhizopus, Chrysonilia, Curvularia, Pestalotiopsis and Fusarium (Table 2). Morphological appearance and growth of some isolates on PDA and MEA plates are presented in Table 3.

The genera Aspergillus, Penicillium, Cladosporium, 
Table 1. Mold counts and $\mathrm{pH}$ of commercial ground coffee and brewed coffee.

\begin{tabular}{|c|c|c|c|c|c|c|}
\hline \multirow{2}{*}{ No. } & \multirow{2}{*}{ Sample Code } & \multirow{2}{*}{ Type of Coffee } & \multicolumn{2}{|c|}{ Mold counts (log CFU/g) } & \multicolumn{2}{|c|}{$\mathrm{pH}$} \\
\hline & & & Before brewing & After brewing & Before brewing & After brewing \\
\hline 1 & KP1 & Robusta-Arabica & $1.2 \pm 0.3^{\mathrm{a}}$ & $\mathrm{NC}$ & $5.80 \pm 0.00$ & $5.55 \pm 0.01$ \\
\hline 2 & KP2 & Robusta & $1.5 \pm 0.2^{\mathrm{a}}$ & $\mathrm{NC}$ & $6.12 \pm 0.01$ & $5.78 \pm 0.08$ \\
\hline 3 & KP3 & Robusta & $1.4 \pm 0.6^{\mathrm{a}}$ & $0.3 \pm 0.4$ & $6.05 \pm 0.01$ & $5.88 \pm 0.01$ \\
\hline 4 & KP4 & Robusta-Arabica & $1.0 \pm 0.0^{\mathrm{a}}$ & $\mathrm{NC}$ & $5.99 \pm 0.01$ & $5.73 \pm 0.01$ \\
\hline 5 & KP5 & Robusta & $1.3 \pm 0.4^{\mathrm{a}}$ & $\mathrm{NC}$ & $6.03 \pm 0.01$ & $5.34 \pm 0.01$ \\
\hline 6 & KP6 & Robusta & $1.2 \pm 0.0^{\mathrm{a}}$ & $\mathrm{NC}$ & $5.54 \pm 0.00$ & $5.26 \pm 0.01$ \\
\hline 7 & KP7 & Robusta-Arabica & $1.0 \pm 0.0^{\mathrm{a}}$ & $0.5 \pm 0.7$ & $5.46 \pm 0.00$ & $5.22 \pm 0.01$ \\
\hline 8 & KP8 & Robusta & $2.3 \pm 0.2^{b}$ & $0.5 \pm 0.2$ & $5.63 \pm 0.00$ & $5.38 \pm 0.00$ \\
\hline 9 & KP9 & Robusta & $1.5 \pm 0.8^{\mathrm{ab}}$ & $0.2 \pm 0.2$ & $5.86 \pm 0.01$ & $5.57 \pm 0.01$ \\
\hline 10 & KP10 & Robusta & $1.5 \pm 0.3^{\mathrm{a}}$ & $\mathrm{NC}$ & $5.36 \pm 0.01$ & $5.30 \pm 0.01$ \\
\hline 11 & KP11 & Robusta & $2.0 \pm 0.5^{\mathrm{ab}}$ & $0.3 \pm 0.0$ & $5.53 \pm 0.01$ & $5.43 \pm 0.00$ \\
\hline 12 & KP12 & Arabica & $1.3 \pm 0.4^{\mathrm{a}}$ & $0.1 \pm 0.1$ & $5.36 \pm 0.00$ & $5.17 \pm 0.00$ \\
\hline 13 & KP13 & Robusta & $2.2 \pm 0.6^{\mathrm{ab}}$ & $0.2 \pm 0.2$ & $5.40 \pm 0.00$ & $5.17 \pm 0.00$ \\
\hline 14 & KP14 & Robusta & $2.2 \pm 0.1^{\mathrm{b}}$ & $\mathrm{NC}$ & $5.59 \pm 0.00$ & $5.20 \pm 0.00$ \\
\hline 15 & KP15 & Arabica & $2.2 \pm 0.0^{\mathrm{b}}$ & $\mathrm{NC}$ & $5.12 \pm 0.00$ & $5.04 \pm 0.00$ \\
\hline
\end{tabular}

$\mathrm{NC}=$ no colonies found

Table 2. Identified mold from commercial ground coffee before brewing

\begin{tabular}{|c|c|c|c|c|}
\hline Genera & Species & Isolate & Frequency & Coffee samples \\
\hline \multirow[t]{2}{*}{ Alternaria } & Alternaria sp. (1) & 12 & 19 & $\mathrm{KP} 3,6,8,9,10,12$ \\
\hline & Alternaria sp. (2) & 27 & 3 & KP 6,8 \\
\hline \multirow{2}{*}{ Aspergillus } & Aspergillus flavus & 41 & 57 & KP $10,11,12$ \\
\hline & Aspergillus niger & 57 & 3 & KP 10,14 \\
\hline \multirow[t]{5}{*}{ Cladosporium } & Cladosporium cladosporioides & 15 & 24 & $\mathrm{KP} 2,4,5,8$ \\
\hline & Cladosporium sp. (1) & 16 & 35 & $\mathrm{KP} 5,8,10,13,14,15$ \\
\hline & Cladosporium sp. (2) & 18 & 2 & KP 5, 14 \\
\hline & Cladosporium sp. (3) & 24 & 22 & $\mathrm{KP} 5,9,14,15$ \\
\hline & Cladosporium sp. (4) & 28 & 2 & KP 7 \\
\hline Chrysonilia & Chrysonilia sp. & 6 & 15 & $\mathrm{KP} 2,11,12,15$ \\
\hline \multirow[t]{2}{*}{ Curvularia } & Curvularia lunata & 44 & 6 & KP 6,14 \\
\hline & Curvularia pallesence & 45 & 3 & KP 10,14 \\
\hline Fusarium & Fusarium sp. & 53 & 1 & KP 15 \\
\hline \multirow[t]{2}{*}{ Geotrichum } & Geotrichum sp. (1) & 1 & 19 & $\mathrm{KP} 1,2,3,14$ \\
\hline & Geotrichum sp. (2) & 4 & 4 & $\mathrm{KP} 1,9$ \\
\hline Pestalotiopsis & Pastalotiopsis sp. & 21 & 2 & KP 5 \\
\hline \multirow[t]{8}{*}{ Penicillium } & Penicillium citrinum & 51 & 3 & KP 15 \\
\hline & Penicillium corylophilum & 50 & 2 & KP 15 \\
\hline & Penicillium islandicum & 31 & 3 & KP 8 \\
\hline & Penicillium sp. (1) & 17 & 2 & KP 5 \\
\hline & Penicillium sp. (2) & 30 & 4 & $\mathrm{KP} 8,15$ \\
\hline & Penicillium sp. (3) & 34 & 3 & KP 9, 14 \\
\hline & Penicillium sp. (4) & 48 & 2 & KP14 \\
\hline & Penicillium sp. (5) & 49 & 20 & $\mathrm{KP} 9,10,12,14,15$ \\
\hline Phoma & Phoma sp. & 13 & 2 & KP 3, 11 \\
\hline Rhizopus & Rhizopus sp. & 40 & 2 & KP 5, 11 \\
\hline
\end{tabular}

and Fusarium were also detected in commercial black coffee powder samples in Malaysia (Rahim et al., 2011). The presence of environmental molds in commercial ground coffee, particularly Aspergillus, Penicillium, and Fusarium is of the most concern because these molds are known to produce harmful mycotoxins to human. Aspergillus flavus was detected in three samples of commercial ground coffee in this study. The presence of
A. flavus in coffee beans has been reported by Alvindia and Acda (2010) after harvest, drying, and on roasted beans from retail markets. A. flavus has also been detected on green coffee during fermentation, drying, and storage in polystyrene and jute sacks (Silva et al., 2008). However, the presence of toxigenic mold in coffee does not always indicate the presence of mycotoxins, since many factors influence the 
biosynthesis of mycotoxin. Production of mycotoxin such as aflatoxin is depending on environment condition, particularly water activity and temperature (Mannaa and Kim, 2017).

Furthermore, molds belonging to genera Fusarium, Pestalotia, Paecelomyces and Penicillium were also detected in coffee cherries, whereas Fusarium, Penicillium as well as Aspergillus were also found in dried coffee beans (Silva et al., 2008). Djossou et al. (2015) also reported that Aspergillus niger, Aspergillus fumigati, Penicillium, Fusarium, and Mucor contaminated coffee beans from Ivory Coast. Alvindia and Acda (2010) reported that molds from different genera were found in roasted beans, such as Aspergillus chevalieri, Aspergillus flavus, A. niger, A. fumigatus, Chrysosporium spp., Microascus spp., Penicillium citrinum, Penicillium janczewskii, and Rhizopus oryzae. Furthermore, Al-Abdalall and Al-Talib (2012) also reported the occurrence of filamentous mold in coffee beans (Coffea arabica L.) from grocery stores and retail markets in an eastern region of the Kingdom of Saudi Arabia. The predominating genera were Aspergillus, with the highest frequency found was $A$. niger (74.71\%). Several molds from other genera were also isolated such as Fusarium solani $(3.56 \%)$, A. flavus $(2.01 \%)$, and Penicillium oxalicum (1.61\%).

Table 3. Macroscopic and microscopic appearance of mold isolates after 7 days of incubation at $25^{\circ} \mathrm{C}$

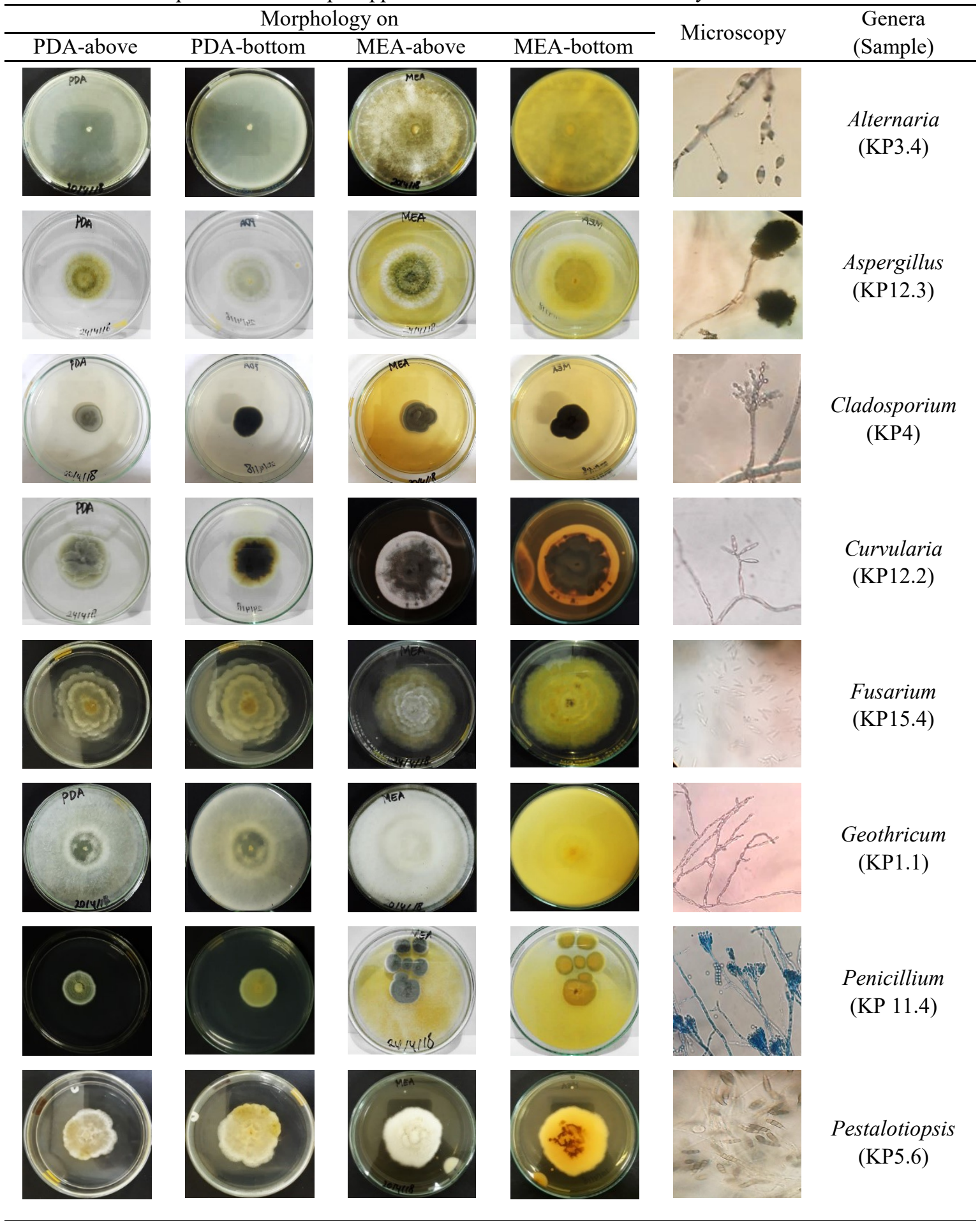


As shown in Table 2, Cladosporium was found as the most often detected on the coffee samples before brewing, i.e. it was found in 10 of 15 samples. Cladosporium was also found in commercial black coffee powder samples in Malaysia, although in a lower frequency than Fusarium (Rahim et al., 2011). Cladosporium is known as the most abundant fungi in outdoor and indoor air (Bensch et al., 2018). The conidium Cladosporium is adaptable in the air because it is small, dry, lightweight, and resistant to sunlight (Pitt and Hocking, 2009). Silva et al. (2008) reported that Cladosporium was detected in coffee cherries collected from trees, during fermentation and was still found after drying and during storage of dried coffee beans.

In this study, although in low counts, mold from genera Alternaria was found in six of ten coffee samples. Alternaria alternata (1.2\%) was also reported by AlAbdalall and Al-Talib (2012) in coffee beans from different grocery stores and retail markets. Alternaria species are generally found as saprophytes and endophytes of a wide range of plants pre- and postharvest (Woudenberg et al., 2013; Lee et al., 2015). Several taxa, however, were also found as important postharvest pathogens and airborne allergens (Woudenberg et al., 2013). In another study, A. alternata together with Cladosporium cladosporioides, Pestalotiopsis sp., Phoma exigua var. exigua and Phoma herbarum, as endophytic fungi, were also isolated from leaves of Coffea arabica L. in Brazil (Fernandes et al., 2009). The author also pointed out that antibacterial, fungicidal and herbicidal activities were showed by a high proportion of endophytic mold. The culture of $A$. alternate was found as potential antibacterial and antifungal source.

The other molds that were identified in this study were from genera Chrysonilia, Pestalotiopsis and Phoma. The species $C$. sitophila formerly was known as Monilia sitophila (Pitt and Hocking, 2009). The genus Chrysonilia includes three species, i.e. C. sitophila, $C$. crassa and $C$. tetrasperma. Chrysonilia sitophila has been reported as an inducer of occupational asthma cases in person involved in the coffee industry (Francuz et al., 2010). Pestalotiopsis isolates were obtained from leaves of Coffea arabica in Southern China (Song et al., 2013). Pestalotiopsis species is known as weak plant pathogens, but also as common endophytes produces bioactive compounds. Phoma is a soil mold that can attack the coffee leaves and cherries. Couto et al. (2014) reported that Phoma was also found on coffee beans under organic and conventional cultivation. Other genera were also found such as Aspergillus, Penicillium, Fusarium, Cladosporium, Mucor, Rhizopus, Trichoderma, Colleototrichum, Epicoccum, Bipolaris, Glomerella,
Colletotricum, Gliocladium and Alternaria. Organic coffee beans demonstrated greater mold diversity than conventional coffee beans.

\subsection{Mold isolates from brewed coffee}

Some molds were recovered after the coffee was brewed in hot water at $90^{\circ} \mathrm{C}$ (Table 4). Some molds were not identified. However, the total molds in brewed coffees decreased to a low level or undetected as presented in Table 1. The temperature applied for coffee brewing in this study was higher than that found in the study of Verst et al. (2018). Verst et al. (2018) studied the dispensing and serving temperatures of coffee-based hot beverages in the home and in the food service industry. The study reported that of 356 coffees in the food service industry and 110 coffees in private households, the dispensing temperatures were in a range of $58-86^{\circ} \mathrm{C}$ with an average at $75 \pm 5^{\circ} \mathrm{C}$.

Table 4. Identified mold from brewed coffee

\begin{tabular}{cccc}
\hline $\begin{array}{c}\text { Sample } \\
\text { Code }\end{array}$ & Type of Coffee & Isolate & Genera \\
\hline \multirow{2}{*}{ KP3 } & Robusta & $2,3,11,14$ & Not identified \\
KP7 & Robusta-Arabica & 55 & Alternaria sp. (1) \\
& & $3,11,14,39$ & Not identified \\
KP8 & Robusta & 12, & Alternaria sp. (1) \\
& & 27 & Alternaria sp. (2) \\
& & 54 & Aspergillus sp. (1) \\
KP9 & Robusta & $2,3,14,39$ & Not identified \\
& & 12 & Alternaria sp. (1) \\
KP11 & Robusta & 3 & Unidentified \\
KP12 & Arabica & 12 & Alternaria sp. (1) \\
KP13 & Robusta & 14 & Not identified \\
& & 39 & Not identified \\
\hline
\end{tabular}

As presented in Table 4, Alternaria sp. (isolate 12 and 27) were found in five samples, whereas Aspergillus sp. (isolate 54 and 55) were found in two samples of brewed coffee. The presence of Alternaria sp. in brewed coffee, indicated that they likely produced spores that could be regarded as heat resistant. Ascospore-forming Aspergillus, together with Byssochlamys, Talaromyces, and Penicillium were reported by Pitt and Hocking (2009) belong to the most commonly occurring heatresistant molds.

In general, the pasteurization process at temperature of $70^{\circ} \mathrm{C}$ for 10 mins can inactivate Aspergillus, Fusarium, Penicillium, Mucor and Rhizopus (Yaguchi et al., 2012). However, Jesenská et al. (1993) reported that A. fumigatus, Aspergillus nidulans, Eupenicillium baarnense and Ulocladium spp. were still recovered after heat treatment at $80^{\circ} \mathrm{C}$ for 60 mins. The survival of Acremonium sclerotigenum, A. ochraceus, Botryotrichum piluliferum, Byssochlamys fulva, Gilmaniella humicola, Neosartorya fischeri, 
Nodulisporium sp. and Talaromyces avellaneus was even still found after heating at $90^{\circ} \mathrm{C}$ for 10 mins.

Furthermore, the heat resistance of molds from genus Aspergillus which were isolated from spoiled pasteurized product has been reported by Berni et al. (2017). The D values in glucose solution of Aspergillus hiratsukae (三Neosartorya hiratsukae), A. neoglaber (三Neosartorya glabra), and A. thermomutatus ( $\equiv$ Neosartorya pseudofischeri) were in a range between 3.7 to $13.5 \mathrm{mins}$ at $87^{\circ} \mathrm{C} ; 1.5$ to $3.5 \mathrm{mins}$ at $90^{\circ} \mathrm{C}$; and 0.3 to 0.4 mins at $95^{\circ} \mathrm{C}$.

\section{Conclusion}

This study showed that a low level of mold was found in commercial ground coffee before brewing, in a range of 10 to $200 \mathrm{CFU} / \mathrm{g}$. Cladosporium, Aspergillus and Penicillium were recovered as prevalent and important genera before brewing. However, the brewing process reduced the mold counts and the diversity of the mycobiota. Aspergillus sp. and Alternaria sp. were still recovered in very low numbers that expected did not appear to pose a health risk. This study also highlighted that the quality and safety of commercial coffee should be regularly monitored, to obtain and/or maintain safe coffee products for the consumers. Investigating the mycoflora of commercial coffee before and after brewing is worthwhile in providing an overview of the safety of coffee products for consumption.

\section{Conflict of Interest}

The authors declared no potential conflict of interest related to the article.

\section{Acknowledgments}

The authors thank Ir. Ina Retnowati at Phytopathology Laboratory of SEAMEO BIOTROP Indonesia for her valuable help and technical assistance during identification of mold isolates. The authors also thank the Department of Food Science and Technology, Faculty of Agricultural and Technology, Bogor Agricultural University for facilitating this research.

\section{References}

Al-Abdalall, A.H.A. and Al-Talib, E.J. (2012). Incidence and distribution of filamentous fungi during storage of coffee beans in eastern region, Kingdom of Saudi Arabia. International Journal of Applied Agricultural Research, 7(2), 83-98.

Alvindia, D.G. and Acda, M.A. (2010). Mycoflora of coffee beans in the Philippines. Journal International Society for Southeast Asian
Agricultural Sciences (ISSAAS), 16(2), 116 -125.

Bensch, K., Groenewald, J.Z., Meijer, M., Dijksterhuis, J., Jurjevi, Z., Andersen, B., Houbraken, J., Crous, P.W. and Samson, R.A. (2018). Cladosporium species in indoor environments. Studies in Mycology, 89, 177-301. https://doi.org/10.1016/ j.simyco.2018.03.002

Berni, E., Tranquillini, R., Scaramuzza, N., Brutti, A. and Bernini, V. (2017). Aspergilli with Neosartoryatype ascospores: heat resistance and effect of sugar concentration on growth and spoilage incidence in berry products. International Journal of Food Microbiology, 258, 81-88. https://doi.org/10.1016/ j.ijfoodmicro.2017.07.008

Couto, F.A., de Souza, S.C., Monteiro, M.C.P., da Silva, D.M., Cirillo, M.A. and Batista, L.R. (2014). Diversity and association of filamentous fungi in coffee beans under organic and conventional cultivation. African Journal of Microbiology Research, 8(26), 2505-2512. https://doi.org/10.5897/ AJMR2013.6571

Djossou, O., Roussos, S., Isabelle, P.G., Macarie, H., Germain, K. and Yoan, L. (2015). Fungal population, including ochratoxin A producing Aspergillus section nigri strain from Ivory Coast coffee bean. African Journal of Agricultural Research, 10(26), 2576-2589. https:// doi.org/10.5897/AJAR2015.9494

Fernandes, M.R.V., de Silva, T.A.C., Pfenning, L.H., da Costa-Neto, C.M., Heinrich, T.A., de Alencar, S.M., de Lima, M.A. and Ikegaki, M. (2009). Biological activities of the fermentation extract of the endophytic fungus Alternaria alternata isolated from Coffea arabica L. Brazilian Journal of Pharmaceutical Sciences, 45(4), 1-10. https:// doi.org/10.1590/S1984-82502009000400010

Francuz, B., Yera, H., Geraut, L. and Bensefa-Colas, L. (2010). Occupational asthma induced by Chrysonilia sitophila in a worker exposed to coffee grounds. Clinical and Vaccine Immunology, 17(10), 16451646. https://doi.org/10.1128/CVI.00134-10

Iamanaka, B.T., Teixeira, A.A., Teixeira, A.R.R., Copetti, M.V., Bragagnolo, N. and Taniwaki, M.H. (2014). The mycobiota of coffee beans and its influence on the coffee beverage. Food Research International, 62, 353-358. https://doi.org/10.1016/ j.foodres.2014.02.033

Jesenská, Z., Piecková, E. and Bernát, D. (1993). Heat resistance of fungi from soil. International Journal of Food Microbiology, 19(3), 187-192. https:// doi.org/10.1016/0168-1605(93)90076-S

Lee, H.B., Patriarca, A. and Magan, N. (2015). 
Alternaria in food: ecophysiology, mycotoxin production and toxicology. Mycobiology, 43(2), 93106. https://doi.org/10.5941/MYCO.2015.43.2.93

Mannaa, M. and Kim, K.D. (2017). Influence of temperature and water activity on deleterious fungi and mycotoxin production during grain storage. Mycobiology, 45(4), 240-254. https:// doi.org/10.5941/MYCO.2017.45.4.240

Noonim, P., Mahakarnchanakul, W., Nielsen, K.F., Frisvad, J.C. and Samson, R.A. (2008). Isolation, identification and toxigenic potential of ochratoxin A -producing Aspergillus species from coffee beans grown in two regions of Thailand. International Journal of Food Microbiology, 128(2), 197-202. https://doi.org/10.1016/j.ijfoodmicro.2008.08.005

Pitt, J.I. and Hocking, A.D. (2009). Fungi and Food Spoilage. $3^{\text {rd }}$ ed. New York: Springer Science and Business Media. https://doi.org/10.1007/978-0-38792207-2

Rahim, S.H.A., Ayob, M.K. and Ramli, N. (2011). Fungal contamination of commercial coffee powder. International Seminar on The Current Research Progress in Sciences and Technology 2011 (ISSTECH 2011). Retrieved on 12 January 2019, from https://www.researchgate.net/ publication/266322185

Silva, C.F., Batista, L.R. and Schwan, R.F. (2008). Incidence and distribution of filamentous fungi during fermentation, drying and storage of coffee (Coffea arabica 1.) beans. Brazilian Journal of Microbiology, 39, 521-526. https://doi.org/10.1590/ S1517-83822008000300022

Song, Y., Geng, K., Zhang, B., Hyde, K.D., Zhao, W., Wei, J., Kang, J. and Wang, Y. (2013). Two new species of Pestalotiopsis from Southern China. Phytotaxa, 126(1), 22-30. https://doi.org/10.11646/ phytotaxa.126.1.2

Sudiyarto, S., Widayanti, S. and Kresna, D.M. (2012). Consumer behavior of kopi tubruk and instant coffee. Journal of Social and Agricultural Economics, 6(3), 1-11.

Verst L.M., Winkler, G. and Lachenmeier, D.W. (2018). Dispensing and serving temperatures of coffee-based hot beverages. Exploratory survey as a basis for cancer risk assessment. Ernahrungs Umschau, 65(4), 64-70.

Woudenberg, J.H.C., Groenewald, J.Z., Binder, M. and Crous, P.W. (2013). Alternaria redefined. Studies in Mycology, 75(1), 171-212. https://doi.org/10.3114/ $\operatorname{sim} 0015$

Yaguchi, T., Imanishi, Y., Matsuzawa, T., Hosoya, K., Hitomi, J. and Nakayama, M. (2012). Method for identifying heat-resistant fungi of the genus Neosartorya. Journal of Food Protection, 75(10), 1806-1813. https://doi.org/10.4315/0362-028X.JFP12-060. 